\title{
Minor Volatile Compounds Profiles of 'Aligoté' Wines Fermented with Different Yeast Strains
}

\author{
Florin VARARU ${ }^{1 *}$, Jaime MORENO-GARCIA ${ }^{2}$, Juan MORENO², \\ Marius NICULAUA ${ }^{1}$, Bogdan NECHITA ${ }^{1}$, Cătălin ZAMFIR $^{1}$, Cintia COLIBABA ${ }^{1}$, \\ Georgiana-Diana DUMITRU ${ }^{1}$, Valeriu V. COTEA ${ }^{1}$
}

${ }^{1}$ University of Agricultural Sciences and Veterinary Medicine, 3 M Sadoveanu Alley, 700490, Iaşi, Romania; florinvararu@yahoo.com ('correspondingauthor) ${ }^{2}$ Department of Agricultural Chemistry, Marie Curie (C3) building, University of Córdoba, Ctra N-IV-a, km 396, 14014-Córdoba, Spain

\begin{abstract}
The aroma of wine can be classified accordingly to its origin, in varietal aroma, pre-fermentative aroma, fermentative aroma and postfermentative aroma. Although a number of flavor components are found in the original grape, the dominant and major compounds contributing to white wines are formed during alcoholic fermentation, in concordance with the yeast strain used. In order to highlight the influence of the yeast strain to the aroma composition of wines, wine samples from 'Aligoté grape variety made with 8 different yeast strains were subjected to stir bar sorptive extraction-gas chromatography-mass spectrometry (SBSE-GC-MS) analyses. Also, a sensorial analysis of the studied wines was performed by a tasting panel consisting of 15 tasters. 38 minor volatile compounds were quantified by SBSE-GC-MS technique. Different concentration of the same compound and different aroma compounds were identified and quantified in wines obtained with different yeast strains. A wine finger printing was obtained by multivariate data analyses of aroma compounds grouped by chemical families. The analytical and sensorial analysis of the wine samples confirms that there are differences in aroma composition of the wines made with different yeast strains.
\end{abstract}

Keywords: compounds, dry wine, fermentation, oenology, sensorial analysis, yeast

\section{Introduction}

'Aligoté' (AL) is a white grape used to make dry white wines, with significant plantings all over Eastern European countries including Romania, Russia, Ukraine, Hungary, Moldova and Bulgaria. It is an early-ripening variety and is more frost resistant than its more renowned cousins, meaning that its presence in these cooler sites is ensured for some time to come. 'Aligoté' is able to produce delicate wines when grown on the chalky soils, but will also thrive in sandier soils. In Romania is one of the most common varieties for white wines production (Rotaru, 2009). Even though it is highly cultivated in Romania, there are only few studies upon it.

Aroma is one of the most important parameters responsible for the quality of wines. An important quantity of aroma compounds is formed during the alcoholic fermentation of must, strictly dependent on the yeast strain (Cotea et al., 2009; Estévez, 2004). In this context, a study of the influence of the yeast strain to aroma composition of 'Aligoté' wines was necessary.

Several analytical extraction techniques have been employed to ensure the full characterization of the volatile profiles of grapes and wines, such as solid-phase extraction (SPE), solid-phase micro extraction (SPME), solvent-assisted flavor evaporation (SAFE), dynamic headspace sampling
(DHS) and liquid extraction with organic solvents (LLE). Special attention has been given to methods which preclude the use of solvents, such as SPME (Bozalongo et al., 2007) and stir bar sorptive extraction (SBSE) (Marín et al., 2005; Tredoux et al., 2008). SBSE technique has been successfully applied in the last few years to aqueous matrices and wine analyses. A recent review by Castro et al. (2008) contains many references to studies that describe the applications of SBSE for the analysis of wine and oenological products, whereas recent articles have been focused on the characterization of grapes by their content in free and glycosidically bound aroma compounds and their use as markers of wine typicity (Arbulu et al., 2013; Gómez et al., 2012; Pedroza et al., 2010).

The aim of this study was to establish the minor aroma compounds profile of 'Aligote' wines fermented with eight different commercial yeast strains, using SBSE-GC-MS technique.

\section{Materials and methods}

Wine samples

Wines obtained from 'Aligoté' grape variety from Vrancea region, Romania, were studied. The wines were produced in the micro winery belonging to the Oenology 
124

department of the University of Agricultural Sciences and Veterinary Medicine, Iasi. Healthy ripped grapes of Vitis vinifera cv. 'Aligoté' collected at the industrial maturity were destemmed, crushed, and the must was homogenized and transferred to 9 glass containers in equal quantities, for the alcoholic fermentation. Eight different pure cultures of selected yeasts were added to unsterilized must, the 9-th must being left without inoculums, as a control (AV0). The pure yeast cultures were different strains of $S$. cerevisiae and they were marked from AV1 to AV8; AV1-AV7 were based on commercial products, while one $S$. cerevisiae yeast was selected from Iasi vineyard by the Research and Development Station for Viticulture and Wine, Iaşi (AV8). The yeast strains selected are the most frequent yeasts used by the wine makers in this region for dry white wines. The fermentation took place in $25 \mathrm{~L}$ glass containers kept in a room at $10^{\circ} \mathrm{C}$, for 20 days.

\section{General characteristics analyses}

The analysis of $\mathrm{pH}$, reducing sugars, titratable acidity and volatile acidity was performed by the official European Union methods (1990). The ethanol content was quantified by oxidation with dichromate according to Crowell and Ough (1979) and measuring the absorbance at $600 \mathrm{~nm}$. The absorbance was measured in a spectrophotometer using 10 $\mathrm{mm}$ path length glass cells.

\section{Gas-chromatographic quantification of minor volatile compounds}

For the determination of the aroma fraction, stir bar sorptive extraction-gas chromatography-mass spectrometry (SBSE-GC-MS) technique was used. The aroma compounds were absorbed on polydimethylsiloxane (PDMS) coated stir bar or Twister, with $0.5 \mathrm{~mm}$ film thickness and $10 \mathrm{~mm}$ length, at room temperature during $100 \mathrm{~min}$ at $1200 \mathrm{rpm}$. The compounds were transferred to a gas chromatograph coupled to a mass detector and provided with a fused silica capillary column (HP-5MS stationary phase $30 \mathrm{~m}$ length, $0.25 \mathrm{~mm}$ internal diameter and $0.25 \mu \mathrm{m}$ film thicknesses). The initial oven temperature was set at $50^{\circ} \mathrm{C}$ (held for 2 $\min$ ), then raised to $190^{\circ} \mathrm{C}$ at $4^{\circ} \mathrm{C} / \mathrm{min}$ and held for $10 \mathrm{~min}$. For mass spectrometry analysis, electron impact mode (EI) at $70 \mathrm{eV}$ was used. The mass range varied from 35 to $550 \mathrm{amu}$ and the detector temperature was $150^{\circ} \mathrm{C}$. Three replicates have been carried for each analysis.

The identification of volatile compounds was based on comparison of the linear retention indexes (LRI) calculated using the Van der Dool and Kratz's equation (1963) with those reported by specialized literature compilated in the NIST web book of Chemistry and on the matching of mass spectra of the compounds with the reference mass spectra of two libraries (Wiley7N and NIST08) coupled with the ChemStation software. The identification of some chromatographic peaks was also confirmed using pure compounds when available. The quantification was performed by the internal standard method, assuming a response factor equal to one. Relative response for each compound was obtained by using the Total Ion Area of the compound of interest divided by the Total Ion Area of the internal standard.

The characterization of the minor aroma compounds' profiles of wines was based on multivariate statistical analysis using Statgraphics Centurion XVI Software Package. The multivariate statistical methods used in this study were Multiple-Sample Comparison (MSC), Multiple-Variable Analysis (MVA) and Cluster Analysis.

\section{Sensory analysis}

The wines were assessed for color, aroma and flavor acceptability by 15 tasters in a panel in accordance with ISO 8586-1:1993. The tasting room was kept at $20^{\circ} \mathrm{C}$ and wines served in tasting glasses certified and coded. Evaluation of the quality of the wines was made using the method according to ISO 4121:2003, with options of desirable (7-9), acceptable (4-6) and undesirable (1-3). The final punctuations were calculated as mean value, taking into account the evaluation of each taster.

\section{Results and discussions}

The general characteristics of wines are shown Table 1. It appears that volatile acidity differs between 0.3 and $0.66 \mathrm{~g}$ acetic acid/L; ethanol between 10.82 and $12.38 \%$ vol, all the wines being semidry to semisweet wines. The final sugar content vary from $6.5 \mathrm{~g} / \mathrm{L}$ (AV4) to $25.2 \mathrm{~g} / \mathrm{L}$ (AV2), the yeast strains used for sample AV4 and AV5 being the ones that fermented faster the sugars in our experimental conditions. It has to be mentioned that the fermentation was stopped at all samples after 20 days, and the room temperature where the glass containers were kept during the fermentation was set at $10^{\circ} \mathrm{C}$, the only variable being the yeast strain.

There have been identified 38 aroma compounds in wines (Tables 2 and 3), out of which 3 (Nerol, Limonene and Terpinolene) were classified as terpenes and nor-isoprenoids, 11 as aldehydes and ketones, 4 as alcohols (3-Methyl-1butanol, Furfuryl alcohol, Hexanol and Phenylethyl alcohol),

Table 1. Physical-chemical parameters (mean and standard deviation, $\mathrm{n}=3$ ) of wines made with different yeast strains

\begin{tabular}{ccccccc}
\hline $\mathrm{I}$ & $\mathrm{pH}$ & $\begin{array}{c}\text { Volatile acidity } \\
(\mathrm{g} / \text { L Acetic acid })\end{array}$ & $\begin{array}{c}\text { Total acidity } \\
(\mathrm{g} / \text { L Tartaric acid })\end{array}$ & Ethanol $(\% \mathrm{vol})$ & Density & $\begin{array}{c}\text { Reduced sugars } \\
(\mathrm{g} / \mathrm{L})\end{array}$ \\
\hline AV0 & $3,09 \pm 0,02$ & $0,47 \pm 0,02$ & $6,2 \pm 0,1$ & $11,05 \pm 0,1$ & $0,996 \pm 0,005$ & $20,6 \pm 0,1$ \\
AV1 & $3,24 \pm 0,01$ & $0,49 \pm 0,02$ & $6,71 \pm 0,09$ & $10,89 \pm 0,07$ & $0,987 \pm 0,001$ & $24,99 \pm 0$ \\
AV2 & $3,223 \pm 0,005$ & $0,45 \pm 0,02$ & $7,07 \pm 0,04$ & $10,82 \pm 0,02$ & $1,004 \pm 0,0001$ & $25,2 \pm 0,2$ \\
AV3 & $3,197 \pm 0,005$ & $0,35 \pm 0,02$ & $7,37 \pm 0,04$ & $11,35 \pm 0,02$ & $0,995 \pm 0,0004$ & $19,7 \pm 0$ \\
AV4 & $3,283 \pm 0,005$ & $0,66 \pm 0$ & $6,84 \pm 0,09$ & $12,38 \pm 0,3$ & $0,975 \pm 0,003$ & $6,5 \pm 0,05$ \\
AV5 & $3,253 \pm 0,005$ & $0,52 \pm 0,02$ & $7,1 \pm 0$ & $12,33 \pm 0,08$ & $0,973 \pm 0,001$ & $8,98 \pm 0$ \\
AV6 & $3,183 \pm 0,005$ & $0,37 \pm 0,02$ & $7,47 \pm 0,04$ & $10,94 \pm 0,08$ & $0,9867 \pm 0,0006$ & $23,56 \pm 0$ \\
AV7 & $3,2 \pm 0,01$ & $0,3 \pm 0$ & $6,92 \pm 0,04$ & $11,73 \pm 0,31$ & $0,9803 \pm 0,0008$ & $14,15 \pm 0$ \\
AV8 & $3,227 \pm 0,005$ & $0,35 \pm 0,02$ & $6,72 \pm 0,04$ & $11,33 \pm 0,03$ & $0,992 \pm 0,001$ & $14,4 \pm 0$ \\
\hline
\end{tabular}


3 as benzene compounds (Benzaldehyde, N-Phenylaniline and Benzophenone), 3 as acids (Octanoic acid, Decanoic acid and Hexadecanoic acid) and 14 as esters (including Ethyl butanoate, Ethyl hexanoate, Ethyl heptanoate, Ethyl octanoate, Ethyl decanoate, Hexyl acetate, Octyl acetate, Hexyl hexanoate etc.) (Moreno, 2012).

This way of grouping the aroma compounds is based on the similarity of structure and functional chemical groups, having as one advantage that the components in the same group have similar aroma descriptors in addition to their similar physical and chemical properties. Terpenes and norisoprenoids usually have floral odor, aldehydes and ketones a herbaceous odor, alcohols show a vinous, sometime 'greenish' odor, benzene compounds have chemical, balsamic odor, while acids have a rancid, dirty, unpleasant odor and esters have a fruit-like odor.

One alcohol (3-Methyl-1-butanol), one acid (Decanoic acid) and two esters (Ethyl octanoate and Ethyl decanoate) registered the greatest values of all the compounds quantified. 3-Methyl-1-butanol have a fusel, alcoholic, pungent, cognac, fruity, banana and molasses odor and registered the highest values at AV3 and AV6 and the lowest values for AV0, AV1 and AV5. Decanoic acid have a metal, mild, fatty, coconut, bay oil odor and registered the highest values at AVS and

Table 2. Non polar compounds identified in wine

\begin{tabular}{|c|c|c|}
\hline No. & Compound Name & CAS \\
\hline 1 & 2-Propanone, 1 -hydroxy- ${ }^{2}$ & $116-09-6$ \\
\hline 2 & 3-Methyl-1-butanol ${ }^{3}$ & $123-51-3$ \\
\hline 3 & Ethyl butanoate $^{6}$ & $105-54-4$ \\
\hline 4 & Furfural $^{2}$ & $98-01-1$ \\
\hline 5 & Furfuryl alcohol ${ }^{3}$ & $98-00-0$ \\
\hline 6 & Hexanol $^{3}$ & $111-27-3$ \\
\hline 7 & Isoamyl acetate $^{6}$ & $123-92-2$ \\
\hline 8 & $2(5 \mathrm{H})$-Furanone $e^{2}$ & $497-23-4$ \\
\hline 9 & 2-Cyclopenten-1-one, 2-hydroxy- ${ }^{2}$ & $10493-98-8$ \\
\hline 10 & Benzaldehyde ${ }^{4}$ & $100-52-7$ \\
\hline 11 & Ethyl hexanoate $^{6}$ & $123-66-0$ \\
\hline 12 & Octanal $^{2}$ & $124-13-0$ \\
\hline 13 & Hexyl acetate ${ }^{6}$ & $142-92-7$ \\
\hline 14 & Limonene $^{1}$ & $138-86-3$ \\
\hline 15 & Terpinolene $^{1}$ & $586-62-9$ \\
\hline 16 & Ethyl heptanoate $^{6}$ & $106-30-9$ \\
\hline 17 & Nonanal $^{2}$ & $124-19-6$ \\
\hline 18 & Phenylethyl alcohol ${ }^{3}$ & $60-12-8$ \\
\hline 19 & Octanoic acid ${ }^{5}$ & $124-07-2$ \\
\hline 20 & 1-Dodecene $e^{2}$ & $112-41-4$ \\
\hline 21 & Ethyl octanoate $^{6}$ & $106-32-1$ \\
\hline 22 & Decanal $^{2}$ & $112-31-2$ \\
\hline 23 & Octyl acetate ${ }^{6}$ & $112-14-1$ \\
\hline 24 & $\mathrm{Nerol}^{1}$ & $106-24-1$ \\
\hline 25 & 2-Phenylethyl acetate ${ }^{6}$ & $103-45-7$ \\
\hline 26 & Decanoic acid ${ }^{5}$ & $334-48-5$ \\
\hline 27 & Hexyl hexanoate ${ }^{6}$ & $6378-65-0$ \\
\hline 28 & 1-Tetradecene ${ }^{2}$ & $1120-36-1$ \\
\hline 29 & Ethyl decanoate ${ }^{6}$ & $110-38-3$ \\
\hline 30 & $\beta$-Phenylethyl butyrate ${ }^{6}$ & $103-52-6$ \\
\hline 31 & 1-Hexadecene ${ }^{2}$ & $629-73-2$ \\
\hline 32 & Ethyl phthalate ${ }^{6}$ & $84-66-2$ \\
\hline 33 & N-Phenylaniline $e^{4}$ & $122-39-4$ \\
\hline 34 & Benzophenone ${ }^{4}$ & $119-61-9$ \\
\hline 35 & Cyclopentaneacetic acid, 3-oxo-2-pentyl-, methyl ester & $24851-98-7$ \\
\hline 36 & 1-Octadecene ${ }^{2}$ & $112-88-9$ \\
\hline 37 & Isobutyl phthalate ${ }^{6}$ & $84-69-5$ \\
\hline
\end{tabular}

AV7 and the lowest values at AV0 and AV1. Ethyl octanoate show odor type as sweet, waxy, fruity and pineapple taste, being predominant in AV4, AV5, AV6 and AV7, with the lowest values in AV0 and AV1, while Ethyl decanoate that shows odor type as waxy, fruity, sweet, apple was predominant in AV4 and AV5 and registered the smallest relative value at AV1 (Table 3). Also, only 15 compounds were found in quantifiable levels in all 9 samples. The other 23 compounds were not found in quantifiable levels in at least one of the samples (Table 3) meaning that the yeast strain had an influence on the minor volatile compounds of wines.

Data obtained by SBSE-GC-MS cannot be considered as an absolute response or content in 'Aligoté" wines because of the limitations of the used Twisters, which are covered with the PDMS adsorbent. This is a non-polar adsorbent and consequently, only the non-polar compounds from the sample are preferentially adsorbed. In this sense, according to Nie and Kleine-Benne (2011) the PDMS Twister does provide a better recovery for non-polar terpene compounds (as alpha-pinene, beta-myrcene, delta-3-carene and d-limonene) then EGSilicone Twister and conversely, this last Twister gives better recovery for more polar compounds as of some hydroxyterpenes (linalool, 4-terpineol, alpha-terpineol and nerolidol).

Compounds were identified by Linear retention index according to Van der Dool and Kratz (1963) in a HP-5MS capillary column $(30 \mathrm{~m} / 0.25 \mathrm{~mm} / 0.25 \mu \mathrm{m}, \mathrm{He})$ and MS spectrum from Willey and NIST libraries. Superscripts indicates the chemical group where the compound was framed: ${ }^{1}$ terpenes and nor-isoprenoids, ${ }^{2}$ aldehydes and ketones, ${ }^{3}$ alcohols, ${ }^{4}$ benzene compounds, ${ }^{5}$ acids, ${ }^{6}$ esters.

By summing the relative area of each of the individual compounds for the 6 established groups it is possible to establish an effective comparison among the studied wines (Fig. 1). This was made by multivariate data analyses, and the graphic presented in Fig. 1 shows the finger printing obtained this way. This plot can be used to group rows with similar characteristics, or to identify unusual cases. In our case, the sunray plot shows that there are differences among the nine samples, AV0 and AV1 being differentiated from the other samples mainly by their content in aldehydes and ketones, AV2 by its content in terpenes and nor-isoprenoids, AV3 and AV6 by their content in alcohols, AV4, AV5 and AV7 by their
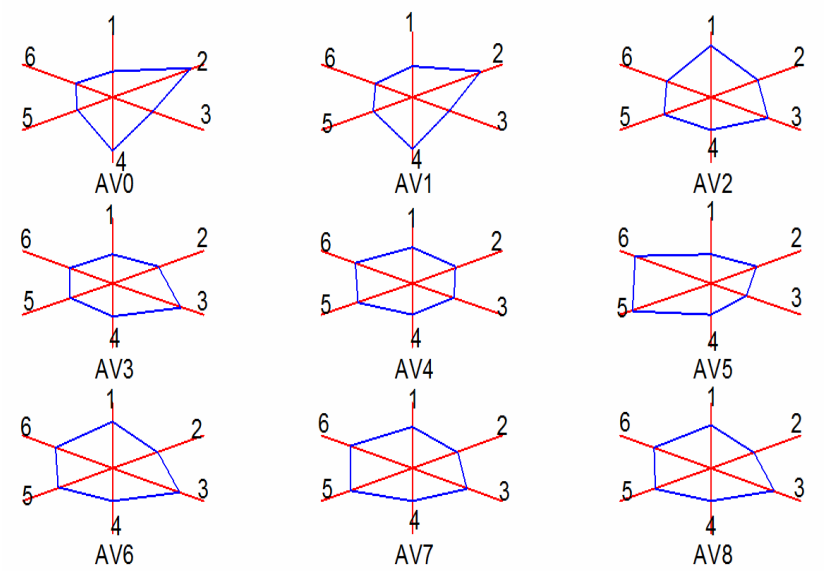

Fig. 1. Wine finger printing obtained by a multivariate data analysis of aroma compounds grouped by chemical families. 1: terpenes and nor-isoprenoids, 2 : aldehydes and ketones, 3: alcohols, 4: benzene compounds, 5: acids, 6: esters 


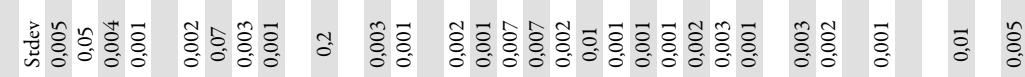
$\frac{\infty}{2}$

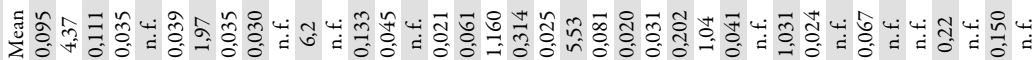

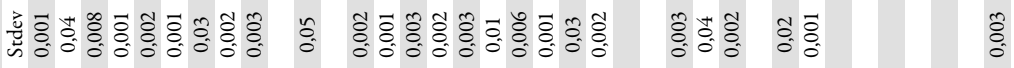
全

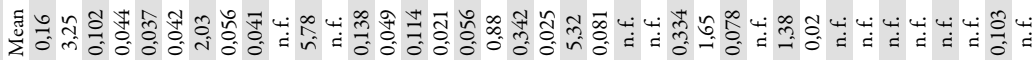

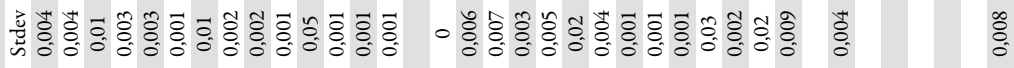
$\stackrel{0}{2}$

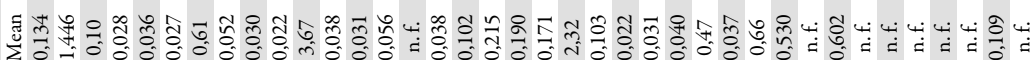

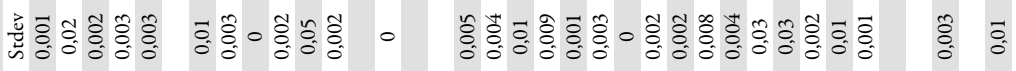
会

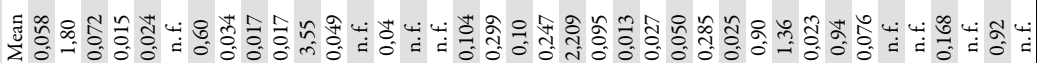

혼 $+\frac{1}{2}$

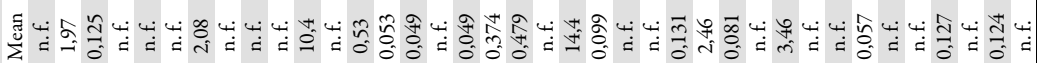

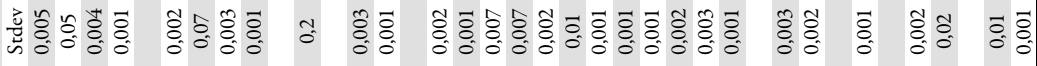
放

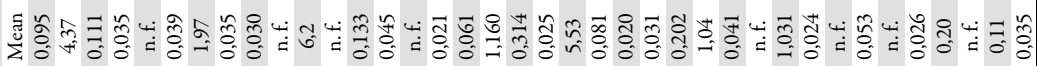

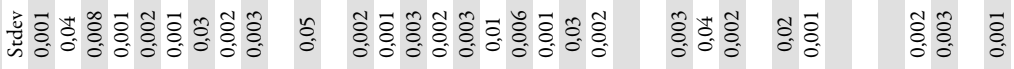
$\frac{1}{2}$

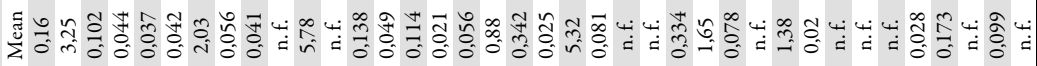

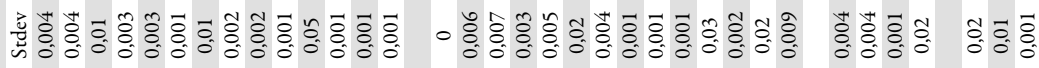
$\sum_{1}$

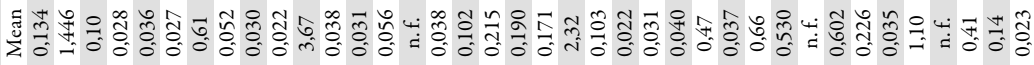

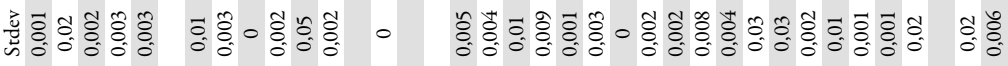
站

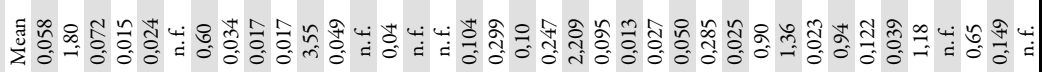

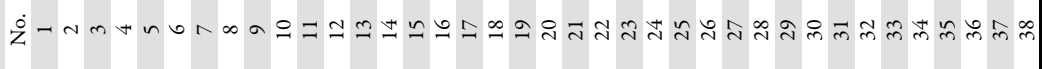


content in acids and esters, while AV8 is differentiated mainly by its content in alcohols jointly with acids and esters.

Also, a cluster analysis was performed using all the aroma compounds quantified, in order to create 1 cluster from the 27 observations supplied (one triplicate for each of the nine samples studied) (Fig. 3). The clusters are groups of observations with similar characteristics. To form the clusters, the procedure began with each observation in a separate group. Besides, it was combined the two observations which were closest together to form a new group. After recomputing the distance between the groups, the two groups then closest together were combined.

This process was repeated until only 1 group remained. The cluster obtained (Fig. 3) shows that it is possible to establish 9 groups by the largest increase in the Euclidean distances among samples matching with the 9 samples studied.

These results reveal that a good differentiation among the wines based on the aroma profile formed by each yeast strain used is possible. The most similar aroma profiles was registered at AV6 and AV7, with AV1 being the sample that have its aroma profile closest to the control sample.

From Fig. 2 one can be concluded that the samples AV6 and AV7 had their aroma profiles similar one to another, the groups formed by these samples being the closest together, meaning that the used yeasts of AV6 and AV7 produced wines with similar characteristics under our experimental conditions. According to the same graph, AV4 and AV8 are also two samples with more or less similar aroma profiles, while AV5 had the most different aroma profile from all the studied samples.

The effect of the yeast strain to the aroma compound profiles of the wines was studied by means of a sensory analysis by a tasting panel. The results (Fig. 2) show that all the samples fermented with selected yeast strains differ comparing with the

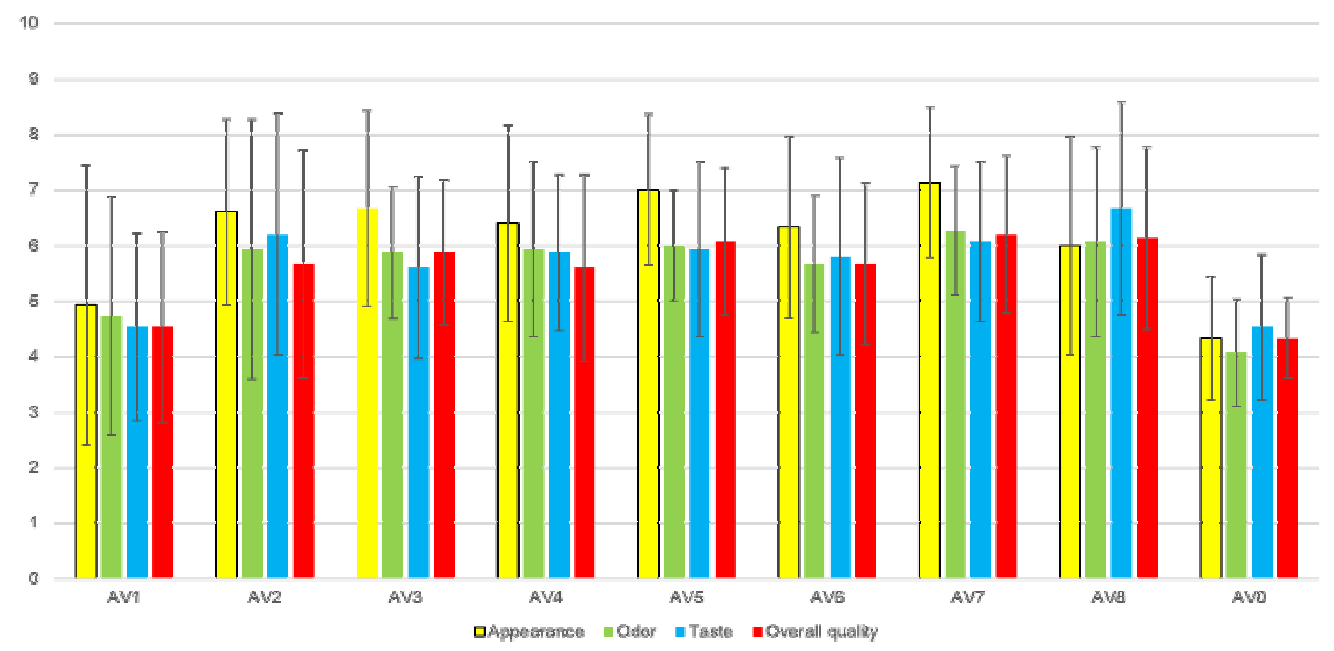

Fig. 2. Sensorial analysis of wines made with different yeast strains

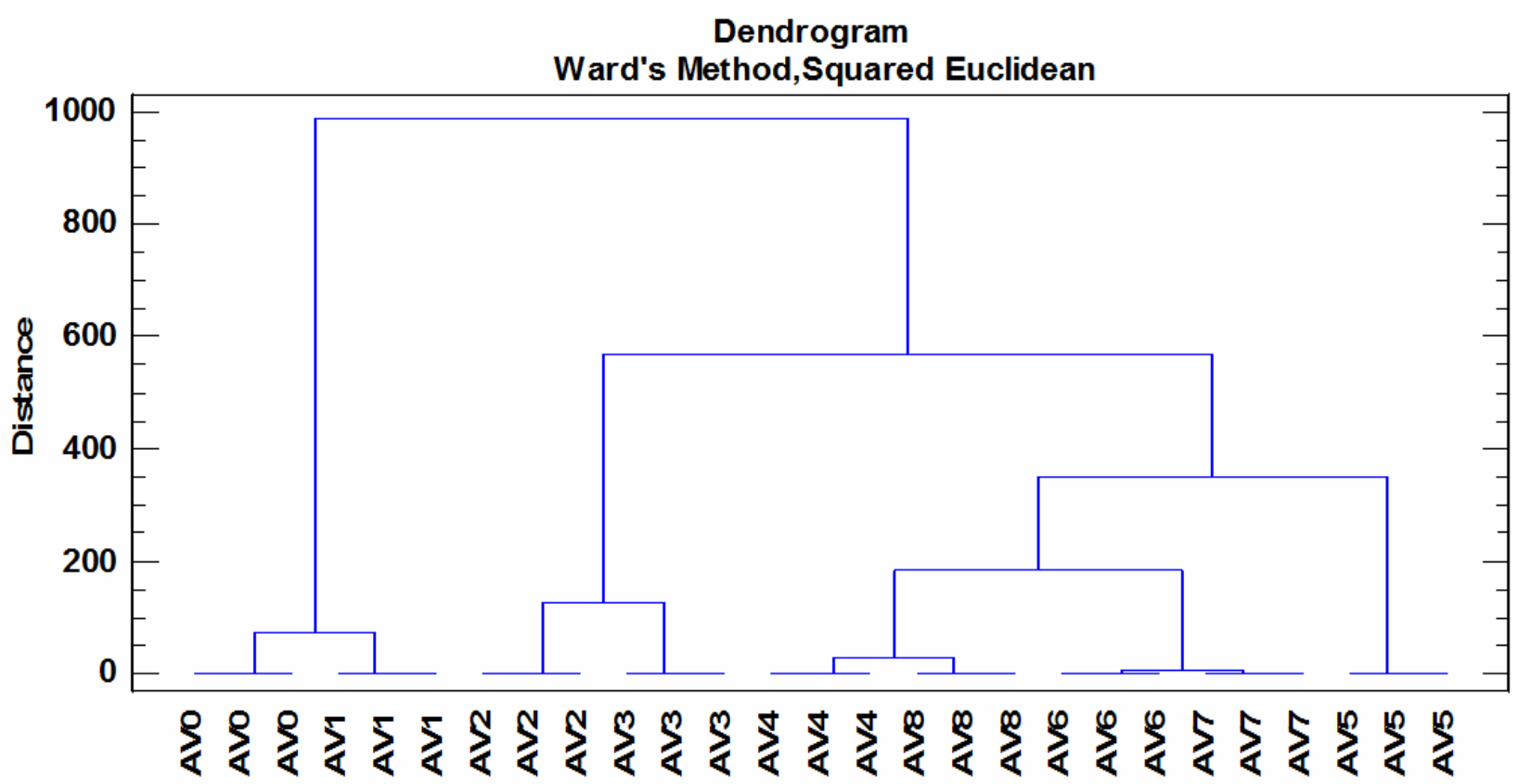

Fig. 3. Cluster analysis of wines fermented with different yeast strains 
128

control sample. The most appreciated samples were AV7 and AV8 and the less appreciated fermented sample was AV1.

\section{Conclusions}

By SBSE-GC-MS technique 38 aroma compounds have been identified in wines fermented with 8 different yeast strains. Only 15 compounds were found in quantifiable levels in all samples, while the other 23 compounds were missing from at least one of the sample, meaning that the yeast strain had an influence on the minor volatile compounds of wines. A wine-fingerprint based on six aroma compound families was obtained, with samples being differentiated according to the relative area of the six aroma compound families established. A good differentiation between the wines aroma profiles was made using cluster analyses as chemometric tool, AV6 and AV7 having the most similar aroma profiles one to another. The sensory analyses carried out by 15 tasters confirm the analytical results. The most appreciated samples were AV7 and AV8 while the less appreciated fermented sample was AV1.

\section{Acknowledgements}

This paper was published under the frame of European Social Fund, Human Resources Development Operational Programme 2007-2013, project no. POSDRU/159/1.5/S/132765. We are grateful to Campus de Excelencia Internacional Agroalimentario (ceiA3) and the International Doctoral Program of the University of Córdoba, in collaboration with Vitenol research Group.

\section{References}

Arbulu M, Sampedro C, Sancez-Ortega A, Gomez-Caballero A, Unceta N, Goicole MA, Barrio RJ (2013). Characterisation of the flavour profile from Graciano Vitis vinifera wine variety by a novel dual stir bar sorptive extraction methodology coupled to thermal desorption and gas chromatography-mass spectrometry. Analytica Chimica Acta 777:41-48.

Bozalongo R, Carrillo JD, Torroba MA, Tena MT (2007). Analysis of French and American oak chips with different toasting degrees by headspace solid-phase microextractiongas chromatography-mass spectrometry. Journal of chromatography 1173:10-7.

Castro R, Natera R, Durán E, García-Barroso C (2008). Application of solid phase extraction techniques to analyse volatile compounds in wines and other enological products. European Food Research and Technology 228(1):1-18.

Cotea VD, Zănoagă CV, Cotea VV (2009). Tratat de Oenochimie, vol. 1, Editura Academiei Române, București.

Estévez P, Gil M, Falqué E (2004). Effects of seven yeast strains on the volatile composition of Palomino wines. International Journal of Food Science and Technology 39:61-69.

Gómez E, Sánchez-Palomo E, Gómez Gallego MA, GonzálezViñas MA (2012). Free and bound volatile compounds as markers of aromatic typicalness of Moravia Dulce, Rojal and Tortosí red wines. Food Chemistry 131:90-98.

Marín J, Zalacain A, De Miguel C, Alonso G, Salinas MR (2005). Stir bar sorptive extraction for the determination of volatile compounds in oak-aged wines. Journal of Chromatography 1098:1-6.

Moreno J, Peinado R (2012). Enological Chemistry, Academic Press.

Nie Y, Kleine-Benne E (2011). Using Three Types of Twister Phases for Stir Bar Sorptive extraction of Whisky, Wine and Fruit Juice, Gerstel Application Note 3:1-13.

NIST. Webbook of Chemistry. http://webbook.nist.gov/chemistry.

Official Journal of the European Communities, L272 (1990). ISSN0257-7763.

Pedroza MA, Zalacain A, Lara JF, Rosario Salinas M (2010). Global grape aroma potential and its individual analysis by SBSE-GC-MS. Food Research International 43:10031008.

Rotaru L (2009). Soiuri de viță de vie pentru struguri de vin, Ed. Ion Ionescu de la Brad, Iaşi.

Tredoux A, Villiers A, Májek P, Lynen F, Crouch A, Sandra P (2008). Stir bar sorptive extraction combined with GC-MS analysis and chemometric methods for the classification of South African wines according to the volatile composition. Journal of Agricultural and Food Chemistry 56:42864296.

Van Den Dool H, Kratz PD (1963). A generalization of the retention index system including linear temperature programmed gas-liquid partition chromatography. Journal of Chromatography 11:463-471. 